\title{
Investing in graduate education
}

\section{In the United States, enrolment in graduate degree programmes in the biological sciences has risen sharply during the global economic downturn, but new graduates face an uncertain job market. What can prospective and current students do to ensure that a graduate degree remains a sound investment?}

Periods of economic instability have historically correlated with increased college and university attendance. Indeed, the recent Survey of Graduate Enrollment and Degrees by the Council of Graduate Schools/ Graduate Record Exam shows that the protracted economic slump in the US has coincided with a surge in graduate school applications and enrolment. According to the report, over 100,000 new applications were made in 2009 for master's or doctoral degree programmes in biological or agricultural sciences (which includes sub-disciplines such as cell and molecular biology). This represents an $8.1 \%$ increase in applications, and a 7.8\% increase in first-time enrolment, from 2008.

Graduates with a degree in the biological sciences have typically faced stiff competition in the job market. But a jump in enrolment, combined with the gloomy economic outlook, has made employment prospects that much more challenging. Although the job market has improved in the past year, widespread furloughs, hiring freezes and budget shortfalls have contributed to a paucity of permanent academic or industry positions. How can students maximize the return on time and energy spent earning a graduate degree? The US National Research Council (NRC), an agency of the US National Academies, has released a report that might help prospective students choose a programme best suited to their interests, thus enabling recent graduates to remain competitive in a difficult job market.

The long-awaited NRC report provides a rich and detailed look at nearly 5,000 individual doctoral programmes at US universities. The report, which is based on data from the 2005-2006 academic years, intentionally avoids ordinal rankings, and instead presents ranking ranges. Twenty characteristics were measured for each programme, including percent of first-year students with full financial support, the median time to degree, attrition rate and the percent of students that plan to remain in academia. The report also indicates the publications and the number of citations per faculty member, and the percent of faculty with awards or grants. Key diversity metrics, such as the percent of female faculty members or of international students, are also reported. Finally, the study provides information about issues that affect the quality of students' personal lives - including availability of health insurance and student activities. The complete report is available for purchase or as a free download.

The NRC has been criticized for providing ranking ranges, rather than a ranked list of programmes, in the report. Moreover, the data are now 5 years old, and there is concern that the report might not provide a current view of graduate school programmes. However, the NRC maintains that the ranking ranges have potentially smaller error, are more widely supported by universities, and also permit students and faculty to evaluate programmes based on personalized criteria. And, despite the possibility that some data are outdated, the report nonetheless provides an important basis for prospective students to begin investigating graduate school programmes, and has generated crucial indicators that university administrators and faculty can use to evaluate and improve their departments.

The unaffiliated PhDs.org website has developed tools that marry the NRC data with those from other sources to allow prospective students to search for programmes that are aligned with their long-term career plans. For example, students interested in teaching can use the tools to identify programmes that provide teaching training, and whose graduates go on to hold academic positions. Individuals focused on academic research after graduation can identify departments or institutions that provide proposal-writing courses and that host research conferences for graduate students. These search criteria can also be combined with time-to-degree and graduation rate, which should be important deciding factors for students regardless of their future plans. However, a limitation of the PhDs.org site is the scarcity of data available for students interested in non-academic scientific careers, such as law or technology transfer.

Most graduate school programmes foster the development of a core set of transferable skills. By the time they graduate, students will have had valuable experience in mentoring through training new graduate or undergraduate students, and applying for pre-doctoral fellowships should provide preparation for writing grant applications. A teaching assistantship, which is also required in many programmes, can provide a taste of what it is like to prepare and deliver lectures. These experiences, combined with a solid foundation in laboratory research and critical thinking, will serve graduates well regardless of their long-term goals.

Students must also seize opportunities to promote their professional development by seeking exposure to the career options that exist outside of academia. Networking with peers and alumni who have chosen different career paths can obviously provide first-hand insight into these jobs, and many institutes and universities provide such opportunities in the form of career fairs and lectures. Students can also gain direct experience in a range of different professions while still in school. Those interested in writing or editorial work can lobby their group leaders or colleagues for opportunities to co-write reviews or book chapters, edit drafts of grants and papers, and co-review manuscripts. In addition, there are internship opportunities for current or recent graduates in writing and journalism, science policy, technology transfer and teaching. Such experiences will not only lend variety to the graduate school experience, but help students form better ideas about their long-term interests before embarking on a professional career. However, student initiative alone will not be sufficient if graduate programme administrators do not also realize the importance of exposing students to myriad potential career paths, and providing avenues for the development of talents suited to non-research-oriented scientific careers.

Although the surge in graduate school enrolment is an encouraging trend, the sluggish job market can add stress and uncertainty to the last years of graduate school. Students can maximize their chances for a successful career by taking full advantage of the wealth of experiences available during their graduate training. 